\title{
Application of Response Surface Methodology to Enhance Phenol Removal from Refinery Wastewater by Microwave Process
}

\author{
Sherif A. Younis, ${ }^{1}$ Waleed I. El-Azab, ${ }^{1}$ Nour Sh. El-Gendy, ${ }^{1}$ Shuokr Qarani Aziz, ${ }^{2}$ \\ Yasser M. Moustafa, ${ }^{1}$ Hamidi Abdul Aziz, ${ }^{3}$ and Salem S. Abu Amr ${ }^{3}$ \\ ${ }^{1}$ Egyptian Petroleum Research Institute, 1 Ahmed El-Zomor Street, El-Zohour Region, Nasr City, Cairo 11727, Egypt \\ ${ }^{2}$ Civil Engineering Department, College of Engineering, University of Salahaddin-Hawler, 44002 SUH, Erbil, Iraq \\ ${ }^{3}$ School of Civil Engineering, Engineering Campus, 14300 Nibong Tebal, Penang, Malaysia
}

Correspondence should be addressed to Nour Sh. El-Gendy; nourepri@yahoo.com

Received 6 January 2014; Accepted 3 April 2014; Published 28 April 2014

Academic Editor: Tanmay Basak

Copyright (C) 2014 Sherif A. Younis et al. This is an open access article distributed under the Creative Commons Attribution License, which permits unrestricted use, distribution, and reproduction in any medium, provided the original work is properly cited.

\begin{abstract}
Phenol contaminated petroleum refinery wastewater presents a great threat on water resources safety. This study investigates the effect of microwave irradiation on removal of different concentrations of phenol in an attempt for petroleum refinery wastewater treatment. The obtained results show that the MW output power and irradiation time have a significant positive effect on the removal efficiency of phenol. The kinetic reaction is significantly affected by initial MW output power and initial phenol concentrations. Response surface methodology (RSM) was employed to optimize and study the interaction effects of process parameters: MW output power, irradiation time, salinity, $\mathrm{pH}$, and $\mathrm{H}_{2} \mathrm{O}_{2}$ concentration using central composite design (CCD). From the CCD design matrix, a quadratic model was considered as an ultimate model $\left(R^{2}=0.75\right)$ and its adequacy was justified through analysis of variance (ANOVA). The overall reaction rates were significantly enhanced in the combined $\mathrm{MW} / \mathrm{H}_{2} \mathrm{O}_{2}$ system as proved by RSM. The optimum values for the design parameters of the $\mathrm{MW} / \mathrm{H}_{2} \mathrm{O}_{2}$ process were evaluated giving predicted phenol removal percentage of $72.90 \%$ through RSM by differential approximation and were confirmed by experimental phenol removal of $75.70 \%$ in a batch experiment at optimum conditions of $439 \mathrm{~W}$ MW power, irradiation time of $24.22 \mathrm{~min}$, salinity of $574 \mathrm{mg} / \mathrm{L}$, pH 5.10 , and initial $\mathrm{H}_{2} \mathrm{O}_{2}$ concentration of $10 \%(\mathrm{v} / \mathrm{v})$.
\end{abstract}

\section{Introduction}

The main recalcitrant organic material found in petroleum refinery wastewater (PRWW) effluent is phenol due to its high water solubility behavior $(86 \mathrm{~g} / \mathrm{L})$ and resistance to conventional physicochemical treatment methods, for example, oil separation, coagulation, and flocculation $[1,2]$. The phenol concentration in the PRWW effluent is generally in the range of $20-200 \mathrm{mg} / \mathrm{L}[3,4]$, while US Environmental Protection Agency, WHO study in 1998, and Environmental Egyptian Law Number 4, 1994 for wastewater considered phenols as priority pollutants and lowered their content in the wastewater stream to less than $1 \mathrm{mg} / \mathrm{L}$ as maximum concentration limit [5]. Due to the phenol propensity to initiate carcinogenic and mutagenic effects on terrestrial as well as aquatic biota and human [6], PRWW effluent needs additional treatment before its final disposal to reduce the phenol concentrations in the wastewaters to accomplish the requirements for discharge in the receiving body and comply with relevant Egyptian and international standards for water recycling and reuse.

Over the past few decades, advanced oxidation processes (AOP) have received increasing attention for the destruction of phenolic pollutants commonly found in wastewaters [7, 8] as it provides total destruction of the pollutant without any generation of byproducts, thereby causing less harm to the environment [9]. Among these AOP, microwave (MW) technology has attracted a great deal of attention as energyefficient AOP to tertiary treatment of different organic pollutants in wastewater [10-13]. 
MW energy belongs to nonclassical source of energy, with separate bands of electromagnetic radiation and frequencies ranging from $300 \mathrm{MHz}$ to $300 \mathrm{GHz}[14,15]$. The application of MW as advanced oxidation technology has already been applied to industrial, domestic, and medical science and treatment of environmental organic pollution, and so forth [16-20]. Applying MW radiation for waste destruction is attracting due to its molecular-level heating which leads to homogeneous and quick thermal reactions [21, 22] as the dipoles within a dielectric material in an alternating MW electric field attempt to realign themselves according to the applied power. The ability to absorb this energy by the molecules depends upon functional groups and volume of the material involved in the process [15, 23-25].

The aim of this work is to use MW irradiation in batch mode as AOP to study the kinetics of phenol removal from PRWW sample to optimize the operating conditions. Due to the reasonable cost and high oxidizing power of hydrogen peroxide as a homogeneous oxidizing agent, response surface methodology (RSM) was applied to optimize and enhance the process of phenol removal throughout a combination system of $\mathrm{MW} / \mathrm{H}_{2} \mathrm{O}_{2}$ to enhance the removal efficiency. The experimental design matrix was developed through a central composite design (CCD) using the studied variables: MW output power, irradiation time, salinity, $\mathrm{pH}$, and initial hydrogen peroxide concentrations.

\section{Materials and Methods}

2.1. Reagents and Apparatus. Analytical grade phenol (>98\% purity) and hydrogen peroxide $(30 \%, \mathrm{w} / \mathrm{v})$ were purchased from Sigma Aldrich, USA, while all other chemical reagents employed in this study were of analytical grade. A stock solution containing $1000 \mathrm{mg} / \mathrm{L}$ phenol was prepared and then diluted to the required concentration using the authentic wastewater solution, according to the experimental conditions. The authentic wastewater (synthetic water) solution used in this work was prepared according to the physicochemical characteristics of petroleum refinery effluents collected from wastewater treatment plant at Cairo Oil Refining Company (CORC) in Egypt at different dates and time intervals (data not shown) and was composed of $\mathrm{NaCl} 0.48 \mathrm{~g}, \mathrm{KCl}$ 0.019 g, $\mathrm{MgSO}_{4} 0.074 \mathrm{~g}, \mathrm{Na}_{2} \mathrm{SO}_{4} 0.009 \mathrm{~g}, \mathrm{CaCl}_{2} 0.12 \mathrm{~g}, \mathrm{MgCl}_{2}$ $0.04 \mathrm{~g}, \mathrm{NaHCO}_{3} 0.18 \mathrm{~g}$, and $\mathrm{CaSO}_{4} 0.03 \mathrm{~g}$, dissolved in $1000 \mathrm{~mL}$ deionized water $(18.2 \mathrm{M} \Omega \mathrm{cm})$.

A modified domestic MW oven (Electrolux, Model EMM2005) with frequency $2450 \mathrm{MHz}$ and maximum output power of 800 Watt was used to supply MW irradiation as shown in Figure 1.

HPLC instrument model Agilent 1200 series equipped with autosampler and photodiode array detector (set at full scan range $190-400 \mathrm{~nm}$ ) was used to analyze the phenol concentrations under the following conditions: $\mathrm{C} 8$ reversed phase $(4.6 \times 25 \mathrm{~cm}, 300 \AA, 5 \mu \mathrm{m})$ column, isocratic program with $60 \%$ acetonitrile: $40 \%$ water $(\mathrm{v} / \mathrm{v})$, flow rate $1.0 \mathrm{~mL} / \mathrm{min}$, and sample size $10 \mu \mathrm{L}$.

2.2. Experimental Conditions. All the experiments were conducted using $\mathrm{MW} / \mathrm{H}_{2} \mathrm{O}_{2}$ system in a $250 \mathrm{~mL}$ capacity quartz

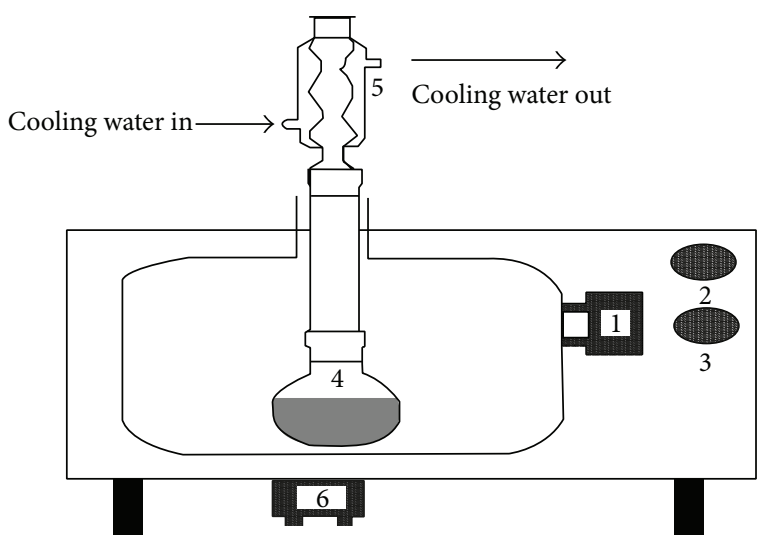

FIgURE 1: Schematic diagram of the MW reactor for PRWW treatment. (1) MW source; (2) time adjuster; (3) power adjuster; (4) pyrex vessel reactor with reaction mixture; (5) condenser connecting with circulating water bath adjusted at $5^{\circ} \mathrm{C} ;(6)$ magnetic stirrer.

flask reactor with a working volume of $25 \mathrm{~mL}$. The phenol solutions with different concentrations $(10,25$, and $50 \mathrm{mg} / \mathrm{L})$ were irradiated at different MW power levels, 100, 150, 300, 450 , and 600 Watt, and at different irradiation times intervals ranging from 1 to $40 \mathrm{~min}$.

The initial salinity of the solution range $(200-1000 \mathrm{mg} / \mathrm{L})$ was adjusted by adding $\mathrm{NaCl}$; initial $\mathrm{pH}$ range $(\mathrm{pH} 5-$ 9) was adjusted by $0.1 \mathrm{M} \mathrm{NaOH}$ or $\mathrm{HCl}$ and the initial $\mathrm{H}_{2} \mathrm{O}_{2}$ concentrations range ( 1 to $10 \% \mathrm{v} / \mathrm{v}$ ) was employed to decontaminate authentic PRWW containing different concentrations of phenol. After the MW removal process, the phenol concentration in the samples was determined using HPLC. The listed removal efficiency by MW was the arithmetic average of the results derived from duplicate experiments.

2.3. Kinetic Study. The kinetic study was carried out at different MW powers (100-600 W) at a fixed initial phenol concentration of $10 \mathrm{mg} / \mathrm{L}$ and at different concentrations of phenol $(10,25$, and $50 \mathrm{mg} / \mathrm{L})$ at a fixed MW output power of $450 \mathrm{~W}$. Three different kinetic models were tested for the obtained data to elucidate the removal processes (1)-(3) as follows:

(1) zero-order kinetic model [26]

$$
C_{t}=-k_{1} t+C_{o},
$$

(2) first-order kinetic model [7]

$$
\ln C_{t}=-k_{2} t+\ln C_{o},
$$

(3) second-order kinetic model [27]

$$
\frac{1}{C_{t}}=-k_{3} t+\frac{1}{C_{o}}
$$

where $C_{o}$ and $C_{t}$ were the initial and final concentration $(\mathrm{mg} / \mathrm{L})$, respectively; while $K_{1}(\mathrm{mg} / \mathrm{min})$, $K_{2}\left(\min ^{-1}\right)$, and $K_{3}\left(\mathrm{mg}^{-1} \mathrm{~min}^{-1}\right)$ are rate constant for zero-, first-, and second-order kinetic models; respectively, and $t$ is irradiation time ( $\mathrm{min})$. 
TABLE 1: The considered levels of independent variables for the phenol removal by CCD.

\begin{tabular}{lcccc}
\hline \multirow{2}{*}{ Independent variables } & \multirow{2}{*}{ Symbol } & \multicolumn{3}{c}{ Variable levels } \\
& & -1 & 0 & +1 \\
\hline (1) $\mathrm{MW}$ Power (Watt) & $A$ & 300 & 450 & 600 \\
(2) $\mathrm{MW}$ Irradiation Time (min) & $B$ & 10 & 20 & 30 \\
(3) Salinity (mg/L) & $C$ & 200 & 600 & 1000 \\
(4) $\mathrm{pH}$ & $D$ & 5 & 7 & 9 \\
(5) $\mathrm{H}_{2} \mathrm{O}_{2}(\% \mathrm{v} / \mathrm{v})$ & $E$ & 1 & 5.5 & 10 \\
\hline
\end{tabular}

2.4. Validity of Kinetic Models. The validity of each model was determined by the following statistical error functions.

(1) The sum of the squares of errors (ERRSQ) [28]

$$
\sum_{i=1}^{n}\left(C_{t, \text { Calc }}-C_{t, \exp }\right)_{i}^{2}
$$

(2) The hybrid fractional error (HYBRID) $[29,30]$

$$
\frac{100}{n-p} \sum_{i=1}^{n}\left|\frac{\left(C_{t, \exp }-C_{t, \mathrm{calc}}\right)_{i}^{2}}{C_{t, \exp }}\right|
$$

where $C_{t, \exp }$ and $C_{t, \text { calc }}$ are the experimental and calculated phenol concentration $(\mathrm{mg} / \mathrm{L})$, respectively, at time $(t)$, and $n$ is the number of data points and $P$ is the number of parameters in the model.

2.5. Experimental Design. The design of experiments was intended to reduce the number of experiments with a wide range of combinations of independent variables. In the present study, CCD with five independent variables, each with three levels (coded as $-1,0$, and +1 for low, medium, and high levels, resp.), was used for the experimental design model (Table 1). The ranges of the independent variables are based on the conditions screened prior to optimization (data not shown). Studies were conducted batchwise according to a statistically designed experimental matrix under $\mathrm{MW} / \mathrm{H}_{2} \mathrm{O}_{2}$ process (Table 2) formulated by the Design Expert 8.0.1.7, (State-Ease Inc., Minneapolis, USA) software in order to map the whole region and obtain reaction conditions at which maximum phenol removal was attained.

The CCD containing a total of 50 experiments with eight replicates at the central points, to estimate the experimental error, was employed to investigate the selected variables effect: initial MW power output, irradiation time (min), salinity, initial $\mathrm{pH}$, and initial hydrogen peroxide concentration $(A, B, C, D$, and $E$, resp.) on the response function (phenol removal\%). The mathematical relationship between the response function $(Y)$ and independent variables $(x)$ was generated to fit a general quadratic polynomial model (6) that was selected as the most appropriate equation to represent the experimental data using response surface regression as follows:

$$
Y=\beta_{o}+\sum_{i=1}^{5} \beta_{i} \chi_{i}+\sum_{i=1}^{5} \beta_{i i} \chi_{i}^{2}+\sum_{i=1}^{4} \sum_{j=i+1}^{5} \beta_{i j} \chi_{i} \chi_{j},
$$

where $Y$ is the predicted response or dependent variable; that is, the phenol removal efficiency (\%) in studied $\mathrm{MW} / \mathrm{H}_{2} \mathrm{O}_{2}$ process, $x_{i}, x_{j}$ are the independent variables, $\beta_{o}$ is the constant model coefficient, $\beta_{i}, \beta_{i i}, \beta_{i j}$ is the interaction coefficient for linear, quadratic, and second-order terms, respectively, calculated from experimental data.

\section{Result and Discussion}

3.1. Kinetics of the Phenol Removal. The trends in the removal of phenol under different MW irradiation power and time intervals experiments are shown in Figure 1. The obtained results revealed that MW irradiation significantly enhances the removal efficiency of phenol. The removal percentage recorded $\approx 28.72 \pm 3.15 \%, 30.0 \pm 2.85 \%, 43.20 \pm 2.90 \%$, $49.43 \pm 1.95 \%$, and $51.26 \pm 2.10 \%$ at $100,150,300,450$, and $600 \mathrm{~W}$ MW after $40 \mathrm{~min}$, respectively.

The removal efficiency for phenol pollutant gradually increased with the increase of the studied MW output power and irradiation time within the range 100-600 W and 1-40 min, respectively. This indicates that MW output power and irradiation time exert a positive effect on phenol removal, that is, enhancing phenol removal efficiency. Similar observation was reported by Papadaki et al. [31] and Zalat and Elsayed [32].

Also, the higher removal efficiency at MW output power $(\geq 300 \mathrm{~W})$ and irradiation time ( $\geq 10 \mathrm{~min}$ ) (Figure 2$)$ indicated that the overall dominating mechanism for explanation of phenol removal by MW could be expressed as thermal cracking (localized pyrolysis or selective heat) caused by oxygen-deficient zones within water due to the heat generated by the absorption of MW energy by water and phenol (hydrophilic nature), which is characterized by a permanent or induced polarization, due to its high dielectric loss factor $[7,33,34]$. Where, the absorption coefficient $(\alpha)$ of MW power is a function of the temperature, that is, a function of MW power and irradiation time intervals [11, 21, 35].

In this study, with the increase of MW irradiation power and time up to 300 Watt and $10 \mathrm{~min}$, respectively, the temperature of authentic wastewater increases to $90^{\circ} \mathrm{C}$ (as recorded by temperature controller) and consequently water transparency leading to deeper penetration of MW radiation to phenol molecules and results increment of MW electromagnetic field absorption; the dipoles within the phenol pollutant attempt to realign themselves according to the applied MW field. This generates internal friction, resulting in high energy absorption by phenol that induced polarization of phenol and thermal removal by pyrolysis to their elemental constituents. This means that phenol removal by MW alone is highly significant. Chien [13] reported that the absorption coefficient decreases from 2.2 to $0.3 \mathrm{~cm}^{-1}$ for water as the temperature increases from 2 to $95^{\circ} \mathrm{C}$.

Furthermore, it can be seen that the removal rate of phenol increases until attaining approximately highest removal values at MW output power of 450 Watt for all studied range of MW power while with higher MW irradiation power $(600 \mathrm{~W})$, more heat could be generated; but no significant removal values were attained. Therefore, in view of cost 
TABLE 2: Design matrix for the phenol decomposition process by CCD.

\begin{tabular}{|c|c|c|c|c|c|c|c|}
\hline \multirow{2}{*}{ Run number } & \multirow{2}{*}{$\begin{array}{c}A \\
\text { MW power (Watt) }\end{array}$} & \multirow{2}{*}{$\begin{array}{c}B \\
\text { Time (min) }\end{array}$} & \multirow{2}{*}{$\begin{array}{c}C \\
\text { Salinity }(\mathrm{mg} / \mathrm{L})\end{array}$} & \multirow{2}{*}{$\begin{array}{c}\mathrm{D} \\
\mathrm{pH}\end{array}$} & \multirow{2}{*}{$\begin{array}{c}E \\
\mathrm{H}_{2} \mathrm{O}_{2}(\%)\end{array}$} & \multicolumn{2}{|c|}{ Phenol decomposition \% } \\
\hline & & & & & & Predicted & Experimental \\
\hline 1 & 600 & 10 & 1000 & 5 & 1 & 44.39 & 47.05 \\
\hline 2 & 600 & 30 & 1000 & 9 & 1 & 36.25 & 38.90 \\
\hline 3 & 600 & 10 & 1000 & 9 & 1 & 27.09 & 17.60 \\
\hline 4 & 600 & 30 & 200 & 9 & 10 & 48.23 & 51.45 \\
\hline 5 & 300 & 10 & 200 & 9 & 10 & 47.36 & 45.47 \\
\hline 6 & 450 & 20 & 1000 & 7 & 5.5 & 54.69 & 68.49 \\
\hline 7 & 600 & 10 & 200 & 5 & 10 & 50.17 & 55.13 \\
\hline 8 & 300 & 10 & 1000 & 5 & 10 & 55.51 & 50.74 \\
\hline 9 & 450 & 20 & 600 & 5 & 5.5 & 61.19 & 69.79 \\
\hline 10 & 300 & 30 & 1000 & 5 & 1 & 49.65 & 59.44 \\
\hline 11 & 600 & 10 & 1000 & 5 & 10 & 56.60 & 51.24 \\
\hline 12 & 300 & 30 & 200 & 9 & 1 & 42.37 & 46.79 \\
\hline 13 & 600 & 30 & 1000 & 5 & 1 & 57.86 & 56.43 \\
\hline 14 & 300 & 10 & 200 & 9 & 1 & 31.50 & 42.70 \\
\hline 15 & 450 & 20 & 600 & 7 & 5.5 & 56.97 & 52.65 \\
\hline 16 & 600 & 30 & 1000 & 9 & 10 & 55.32 & 59.92 \\
\hline 17 & 300 & 10 & 1000 & 9 & 1 & 24.02 & 27.21 \\
\hline 18 & 600 & 10 & 200 & 5 & 1 & 50.47 & 57.31 \\
\hline 19 & 450 & 20 & 600 & 7 & 5.5 & 56.97 & 57.76 \\
\hline 20 & 300 & 30 & 200 & 5 & 10 & 65.84 & 66.90 \\
\hline 21 & 450 & 20 & 600 & 7 & 5.5 & 56.97 & 51.08 \\
\hline 22 & 600 & 30 & 200 & 5 & 10 & 63.17 & 65.84 \\
\hline 23 & 450 & 20 & 600 & 7 & 10 & 68.50 & 67.44 \\
\hline 24 & 300 & 30 & 200 & 5 & 1 & 59.87 & 59.12 \\
\hline 25 & 600 & 20 & 600 & 7 & 5.5 & 50.04 & 55.97 \\
\hline 26 & 450 & 20 & 600 & 7 & 1 & 55.22 & 63.61 \\
\hline 27 & 300 & 10 & 200 & 5 & 1 & 44.68 & 30.39 \\
\hline 28 & 600 & 30 & 1000 & 5 & 10 & 68.57 & 59.21 \\
\hline 29 & 300 & 10 & 200 & 5 & 10 & 52.17 & 58.85 \\
\hline 30 & 600 & 30 & 200 & 9 & 1 & 41.67 & 44.81 \\
\hline 31 & 600 & 30 & 200 & 5 & 1 & 64.98 & 58.57 \\
\hline 32 & 450 & 20 & 600 & 9 & 5.5 & 47.97 & 46.70 \\
\hline 33 & 450 & 20 & 600 & 7 & 5.5 & 56.97 & 55.90 \\
\hline 34 & 300 & 10 & 1000 & 5 & 1 & 35.51 & 32.43 \\
\hline 35 & 300 & 20 & 600 & 7 & 5.5 & 49.84 & 51.24 \\
\hline 36 & 300 & 10 & 1000 & 9 & 10 & 52.39 & 52.58 \\
\hline 37 & 600 & 10 & 1000 & 9 & 10 & 47.68 & 55.38 \\
\hline 38 & 450 & 20 & 600 & 7 & 5.5 & 56.97 & 53.91 \\
\hline 39 & 600 & 10 & 200 & 9 & 10 & 39.55 & 30.50 \\
\hline 40 & 450 & 20 & 600 & 7 & 5.5 & 56.97 & 48.94 \\
\hline 41 & 450 & 10 & 600 & 7 & 5.5 & 49.44 & 57.21 \\
\hline 42 & 300 & 30 & 1000 & 5 & 10 & 68.14 & 70.31 \\
\hline 43 & 300 & 30 & 1000 & 9 & 1 & 33.85 & 20.30 \\
\hline 44 & 450 & 30 & 600 & 7 & 5.5 & 60.85 & 60.42 \\
\hline 45 & 300 & 30 & 1000 & 9 & 10 & 60.72 & 61.00 \\
\hline 46 & 300 & 30 & 200 & 9 & 10 & 56.72 & 54.63 \\
\hline 47 & 450 & 20 & 600 & 7 & 5.5 & 56.97 & 54.68 \\
\hline 48 & 450 & 20 & 600 & 7 & 5.5 & 56.97 & 51.46 \\
\hline 49 & 600 & 10 & 200 & 9 & 1 & 31.48 & 28.20 \\
\hline 50 & 450 & 20 & 200 & 7 & 5.5 & 55.73 & 49.27 \\
\hline
\end{tabular}




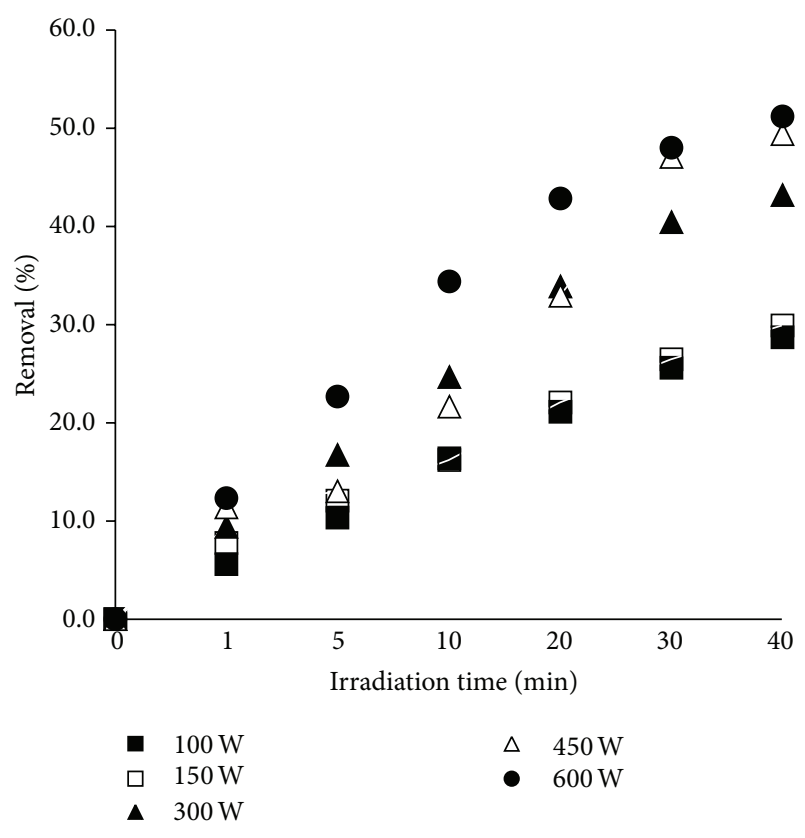

Figure 2: Removal of $10 \mathrm{mg} / \mathrm{L}$ phenol under different MW irradiation powers (100-600 Watt) and time intervals (1-40 min).

effectiveness and MW power saving, the fixed output MW power of $450 \mathrm{~W}$ was chosen for further experiments as an optimum MW power to study the effect of different initial phenol concentrations $(10-50 \mathrm{mg} / \mathrm{L})$ on their removal by $\mathrm{MW}$ treatment system.

The profiles of phenol illustrating the removal efficiency with time at different concentrations $(10-50 \mathrm{mg} / \mathrm{L})$ at a fixed MW output power $450 \mathrm{~W}$ are depicted in Figure 3. It can be observed that the removal efficiency (\%) for phenol at the studied concentrations range was almost unchanged under MW treatment process recording $\approx 49.43 \pm 0.95,52.29 \pm 0.40$, and $50.42 \pm 1.02 \%$ after $40 \mathrm{~min}$ at $10 \mathrm{mg} / \mathrm{L}, 25 \mathrm{mg} / \mathrm{L}$, and $50 \mathrm{mg} / \mathrm{L}$ initial phenol concentration, respectively. This indicates that the removal efficiency of phenol by MW irradiation was not factor of the studied initial phenol concentrations while it was a factor of MW irradiation power and time interval.

The kinetic study of phenol removal was analyzed using the experimental data obtained with various initial MW power (100-600 W) and different initial phenol concentrations $(10-50 \mathrm{mg} / \mathrm{L})$. The correlation coefficient $\left(R^{2}\right)$, the rate constant $(K)$, half-lives $\left(t_{1 / 2}\right)$, and the statistical error analysis values for studied kinetic models are listed in Tables 3(a) and $3(\mathrm{~b})$. Due to the high correlation coefficient $\left(R^{2}\right)$ values for all kinetic models for studied experiments, the statistical error analysis values were used to confirm the fitting of kinetic models with experimental data. According to the results listed in Tables 3(a) and 3(b), the experimental data for phenol removal at different MW output power were best fitted with zero-order kinetic model at low MW irradiation power $(100$ and $150 \mathrm{~W})$ with $R^{2}$ values $\approx 0.97$ and lowest error analysis values as represented in Figure 4(a); however, under higher MW irradiation power range from 300 to $600 \mathrm{~W}$, the

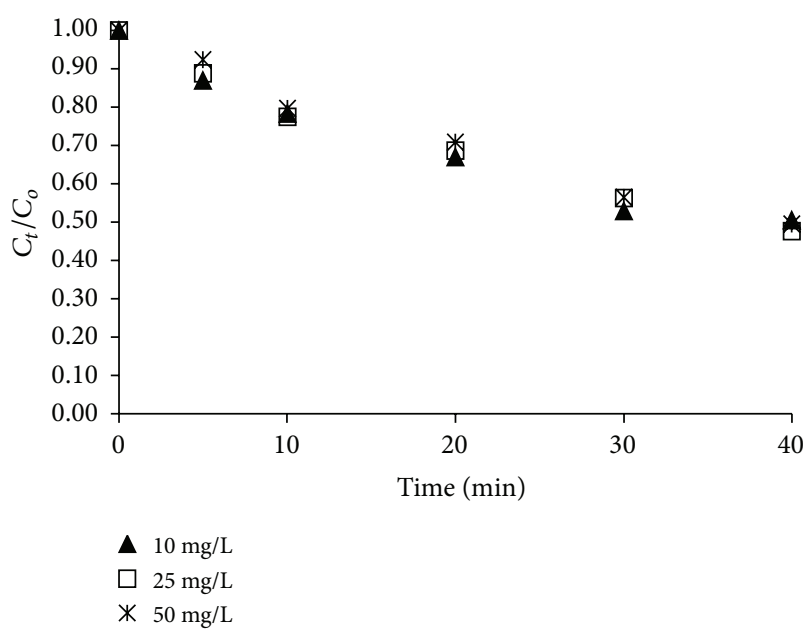

FIGURE 3: Effect of initial phenol concentration on removal efficiency by MW at $450 \mathrm{~W}$.

observed kinetics shifted to first-order kinetic model with lowest error analysis values and $R^{2}$ values of $0.97-0.99$ higher than that of the zero-order kinetic model $\left(R^{2} 0.75-0.94\right)$ as represented in Figure 4(b). Furthermore, the experimental data at different initial phenol concentrations were best fitted with a first-order kinetic model with $R^{2}$ values of 0.99 and lowest error analysis values under MW treatment at phenol concentration range from 10 to $25 \mathrm{mg} / \mathrm{L}$. However, under higher phenol concentration of $50 \mathrm{mg} / \mathrm{L}$, the observed kinetics shifted to second-order kinetic model with $R^{2}$ values of 0.99 and lowest error analysis values as illustrated in Figure 5.

Obviously, from the results listed in Tables 3(a) and 3(b), it can be observed that the initial MW output power and phenol concentrations had influence on both of the rate constants $(K)$ and half-lives $\left(t_{1 / 2}\right)$; the rate constants increased and halflives decreased gradually as the MW output power increased up to 450 Watt MW power with approximately no significant difference between $450 \mathrm{~W}$ and $600 \mathrm{~W}$ MW output power. While the $t_{1 / 2}$ had no significant difference between different initial phenol concentrations at fixed output MW power of 450 watt. These observations could confirm that the removal efficiency of phenol by MW irradiation does not depend on phenol concentrations, although it significantly depends on MW irradiation power.

Zhao et al. [36] and Zhao and Fei [37] reported that, under MW irradiation alone at $750 \mathrm{~W}$, phenol is degraded slowly via pyrolysis with a pseudofirst-order kinetic. Additionally, Prasannakumar et al. [7] reported that phenol removal by MW irradiation $(180 \mathrm{~W})$ at different concentrations (100$500 \mathrm{mg} / \mathrm{L}$ ) in the presence of $\mathrm{H}_{2} \mathrm{O}_{2}$ followed the first-order kinetic model.

3.2. Process Optimization and Interactions between Independent Variables. RSM was successfully used in optimizing the studied parameters (i.e., output MW power, irradiation time, salinity, $\mathrm{pH}$, and initial hydrogen peroxide concentration) for removal of phenol at $10 \mathrm{mg} / \mathrm{L}$ concentration 


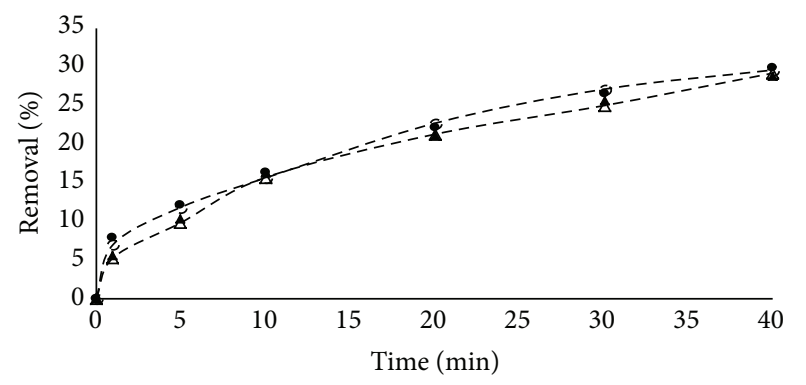

- $100 \mathrm{~W}$-experimental data $\quad-\Delta-100 \mathrm{~W}$ zero-order kinetic

- $150 \mathrm{~W}$-experimental data $\quad$-s- $150 \mathrm{~W}$ zero-order kinetic

(a) $100-150$ Watt

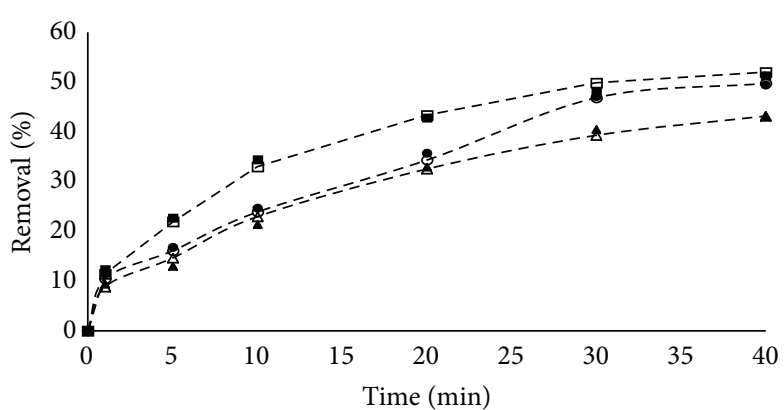

- $300 \mathrm{~W}$-experimental data

- $450 \mathrm{~W}$-experimental data

- $600 \mathrm{~W}$-experimental data
- A- $300 \mathrm{~W}$-first-order kinetic - $\ominus$ - $450 \mathrm{~W}$-first-order kinetic -曰- $600 \mathrm{~W}$-first-order kinetic

(b) 300-600 Watt

FIGURE 4: Comparison between experimental and theoretical removal efficiency on $10 \mathrm{mg} / \mathrm{L}$ phenol at different MW irradiation power (100$600 \mathrm{~W}$ ) (symbols, experimental results; line, theoretical results).

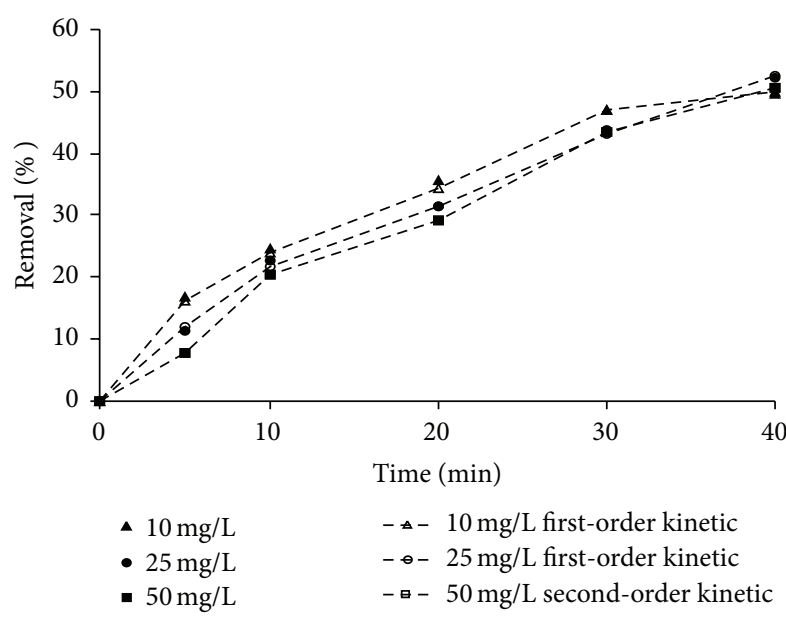

Figure 5: Comparison between experimental and theoretical removal efficiency of phenol at different initial phenol concentrations (10-50 mg/L) (symbols, experimental results; line, theoretical results).

by $\mathrm{MW} / \mathrm{H}_{2} \mathrm{O}_{2}$ operation. The experimental design matrix derived from CCD and the experimental and predicted percentage removals of phenol (response) are shown in Table 2. A total of 50 experiments were required to calculate twenty coefficients of the quadratic model equation and the percentage removal of phenol was taken as the response of the system. From the CCD design, the following quadratic equation (7) can be considered as the ultimate model resulting from statistical analysis in terms of coded factors for removal efficiency of phenol under $\mathrm{MW} / \mathrm{H}_{2} \mathrm{O}_{2}$ treatment system as follows:

$$
\begin{aligned}
Y_{\mathrm{MW}}= & -47.6478+0.32609 A+1.81231 B \\
& -59.3751 \times 10^{-4} \mathrm{C}+6.71491 D
\end{aligned}
$$

$$
\begin{aligned}
& -2.3867 E-3.12368 \times 10^{-4} A^{2} \\
& -18.214 \times 10^{-3} B^{2}-10.9588 \times 10^{-6} C^{2} \\
& -0.5968 D^{2}+0.24163 E^{2}-11.2134 \\
& \times 10^{-5} A B+12.8939 \times 10^{-6} A C \\
& -4.846 \times 10^{-3} A D-2.88442 \times 10^{-3} A E \\
& -64.7831 \times 10^{-6} B C-53.935 \\
& \times 10^{-3} B D-83.8298 \times 10^{-4} B E \\
& +53.1206 \times 10^{-5} C D+17.3821 \\
& \times 10^{-4} C E+0.23244 D E .
\end{aligned}
$$

The quality of the models fitted was judged from coefficients of correlation $\left(R^{2}\right)$. Also, the validity of the fitted model was evaluated through analysis of variance (ANOVA) and its statistical significance was controlled by $F$-test [38]. The analysis of variance (ANOVA) for quadratic model is given in Table 4.

The value of the determination coefficient $\left(R^{2}\right)$ for the quadratic polynomial model (7) was calculated to be 0.75 . This means that approximately $75 \%$ of the variance is attributed to the variables and indicated a moderate significance of the model with $25 \%$ of the total variations not satisfactorily explained by the model. Confirmation of the adequacy of the regression model was reflected also by the good agreement between experimental and predicted values of response variables as shown in Table 2 which ensures the good adjustment of the above model to experimental data. Where, the actual removal efficiency ranged from 17.6 to $70.31 \%$ and its corresponding predicted values are $27.09 \%$ and $68.14 \%$, respectively. "Adeq Precision" measures the signal to noise ratio. A ratio greater than 4 is desirable. The ratio of 
TABLE 3: (a) Kinetic model parameters for decomposition of $10 \mathrm{mg} / \mathrm{L}$ phenol at different initial MW output powers (Watt). (b) Reaction rate constants $(K)$ observed on decomposition of phenol with different initial concentrations $\left(C_{0}\right)$ at 450 Watt MW power.

(a)

\begin{tabular}{lccccc}
\hline Initial MW output power & 100 & 150 & 300 & 450 & 600 \\
\hline Zero-order kinetics & & & & & \\
$R^{2}$ & 0.97 & 0.97 & 0.87 & 0.94 & 0.75 \\
$K_{1}(\mathrm{mg} / \mathrm{min})$ & 0.065 & 0.065 & 0.099 & 0.119 & 0.114 \\
$t_{1 / 2}(\mathrm{~min})$ & 76.57 & 76.57 & 50.35 & 42.19 & 44.01 \\
ERRSQ & 12.12 & 0.52 & 4.94 & 13.05 & 38.74 \\
HYBRID & 33.76 & 2.22 & 23.979 & 19.86 & 215.54 \\
First-order kinetics & & & & & \\
$R^{2}$ & 0.96 & 0.97 & 0.98 & 0.98 & 0.97 \\
$K_{2}\left(\mathrm{~min}^{-1}\right)$ & 0.008 & 0.008 & 0.013 & 0.017 & 0.017 \\
$t_{1 / 2}\left(\mathrm{~min}^{2}\right)$ & 88.87 & 87.74 & 51.73 & 41.01 & 41.51 \\
ERRSQ $_{\text {HYBRID }}$ & 19.74 & 2.54 & 4.33 & 10.52 & 3.67 \\
Second-order kinetics $^{2}$ & 52.173 & 8.21 & 17.45 & 14.67 & 23.252 \\
$R^{2}$ & & & & & \\
$K_{3}$ (mg $^{-1}$ min $\left.^{-1}\right)$ & 0.97 & 0.98 & 0.99 & 0.99 & 0.97 \\
$t_{1 / 2}\left(\mathrm{~min}^{2}\right)$ & 0.001 & 0.001 & 0.002 & 0.003 & 0.003 \\
ERRSQ $_{\text {HYBRID }}$ & 111.11 & 100.00 & 52.63 & 40.00 & 40.00 \\
HYR $^{2}$ & 28.40 & 8.29 & 16.759 & 11.58 & 19.68 \\
\hline
\end{tabular}

Half-life for zero-order: $t_{1 / 2}=\left[C_{0}\right] / 2 k$; first-order: $t_{1 / 2}=\ln (2) / k$; secondorder: $t_{1 / 2}=1 / k\left[C_{0}\right]$.

(b)

\begin{tabular}{lccc}
\hline Initial phenol concentrations & $10 \mathrm{mg} / \mathrm{L}$ & $25 \mathrm{mg} / \mathrm{L}$ & $50 \mathrm{mg} / \mathrm{L}$ \\
\hline Zero-order kinetics & & & \\
$R^{2}$ & 0.94 & 0.97 & 0.97 \\
$K_{1}(\mathrm{mg} / \mathrm{min})$ & 0.119 & 0.314 & 0.633 \\
$t_{1 / 2}(\mathrm{~min})$ & 42.19 & 39.83 & 39.48 \\
ERRSQ & 13.05 & 66.98 & 27.25 \\
HYBRID & 19.86 & 33.93 & 63.65 \\
First-order kinetics & & & \\
$R^{2}$ & 0.98 & 0.99 & 0.99 \\
$K_{2}\left(\mathrm{~min}^{-1}\right)$ & 0.017 & 0.018 & 0.018 \\
$t_{1 / 2}\left(\mathrm{~min}^{2}\right)$ & 41.01 & 38.51 & 38.94 \\
ERRSQ $^{\text {HYBRID }}$ & 10.52 & 47.91 & 26.97 \\
Second-order kinetics $^{2}$ & 14.67 & 25.55 & 56.98 \\
$\mathrm{R}^{2}$ & & & \\
$K_{3}\left(\mathrm{mg}^{-1} \cdot\right.$ min $\left.^{-1}\right)$ & 0.98 & 0.99 & 0.99 \\
$t_{1 / 2}\left(\mathrm{~min}^{2}\right)$ & 0.003 & 0.001 & 0.0005 \\
ERRSQ $_{\text {HYBRID }}$ & 40.00 & 36.36 & 40.00 \\
& 11.58 & 57.47 & 23.94 \\
& 16.74 & 29.15 & 33.85 \\
\hline
\end{tabular}

Half-life for zero-order: $t_{1 / 2}=\left[C_{0}\right] / 2 k$; first-order: $t_{1 / 2}=\ln (2) / k$; secondorder: $t_{1 / 2}=1 / k\left[C_{0}\right]$.

8.475 indicated an adequate signal. This model is reliable and can be used to navigate the design space.

ANOVA analysis (Table 4) indicated that the model is statistically significant at 95\% confidence level (Table 4 ),
TABLE 4: ANOVA test for the phenol removal efficiency.

\begin{tabular}{|c|c|c|c|c|c|}
\hline Source & $\begin{array}{l}\text { Sum of } \\
\text { squares }\end{array}$ & df & $\begin{array}{l}\text { Mean } \\
\text { square }\end{array}$ & $F$ Value & $\begin{array}{c}P \text { value } \\
\text { Prob }>F\end{array}$ \\
\hline Model & 5564.95 & 20 & 278.25 & 4.23 & 0.0002 \\
\hline$A$ & 0.34 & 1 & 0.34 & $5.201 E-003$ & 0.9430 \\
\hline$B$ & 1107.51 & 1 & 1107.51 & 16.84 & 0.0003 \\
\hline C & 9.21 & 1 & 9.21 & 0.14 & 0.7109 \\
\hline$D$ & 1483.81 & 1 & 1483.81 & 22.56 & $<0.0001$ \\
\hline$E$ & 1498.65 & 1 & 1498.65 & 22.79 & $<0.0001$ \\
\hline$A^{2}$ & 122.19 & 1 & 122.19 & 1.86 & 0.1833 \\
\hline$B^{2}$ & 8.18 & 1 & 8.18 & 0.12 & 0.7268 \\
\hline$C^{2}$ & 7.61 & 1 & 7.61 & 0.12 & 0.7362 \\
\hline$D^{2}$ & 14.11 & 1 & 14.11 & 0.21 & 0.6466 \\
\hline$E^{2}$ & 59.17 & 1 & 59.17 & 0.90 & 0.3507 \\
\hline$A B$ & 0.91 & 1 & 0.91 & 0.014 & 0.9071 \\
\hline$A C$ & 19.16 & 1 & 19.16 & 0.29 & 0.5935 \\
\hline$A D$ & 67.63 & 1 & 67.63 & 1.03 & 0.3189 \\
\hline$A E$ & 121.29 & 1 & 121.29 & 1.84 & 0.1849 \\
\hline$B C$ & 2.14 & 1 & 2.14 & 0.033 & 0.8580 \\
\hline$B D$ & 37.24 & 1 & 37.24 & 0.57 & 0.4578 \\
\hline$B E$ & 4.58 & 1 & 4.58 & 0.070 & 0.7938 \\
\hline$C D$ & 5.78 & 1 & 5.78 & 0.088 & 0.7690 \\
\hline$C E$ & 313.38 & 1 & 313.38 & 4.77 & 0.0373 \\
\hline$D E$ & 140.03 & 1 & 140.03 & 2.13 & 0.1552 \\
\hline Residual & 1907.00 & 29 & 65.76 & & \\
\hline $\begin{array}{l}\text { Lack of } \\
\text { fit }\end{array}$ & 1850.33 & 22 & 84.11 & 10.39 & 0.0020 \\
\hline $\begin{array}{l}\text { Pure } \\
\text { error }\end{array}$ & 56.67 & 7 & 8.10 & & \\
\hline Cor total & 7471.95 & 49 & & & \\
\hline
\end{tabular}

with Fisher's test ( $F$ value) of 4.23 and very low probability ( $P$ value) of 0.0002 . The lack of fit test is performed by comparing the viability of the current model residuals to the variability between observations at replicate settings of the factors. The lack of fit was statistically significant with $F$ value of 10.39 and $P$ value of 0.002 . A significant lack of fit suggests that there may be some systematic variation unaccounted for in the hypothesized model [39]. This may be due to the exact replicate values of the independent variables in the model that provide an estimate of pure error. Therefore, the form of the model was chosen (quadratic model) to explain the relationship between the studied independent factors and the response (phenol removal \%) was found to satisfactorily represent the present phenol removal process. Similar observation was reported by Prasannakumar et al. [7].

The empirical predicted quadratic model for response (phenol removal \%) in terms of process variables is plotted in three-dimensional (3D) diagrams (Figure 6) to investigate the interaction among the variables and to determine the optimum combination of studied parameters for maximum removal efficiency of phenol from aqueous solution. 


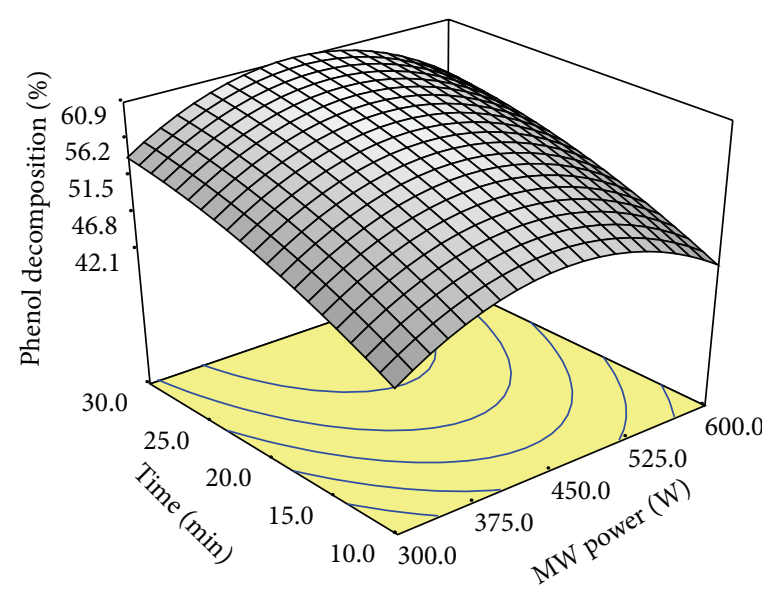

(a)

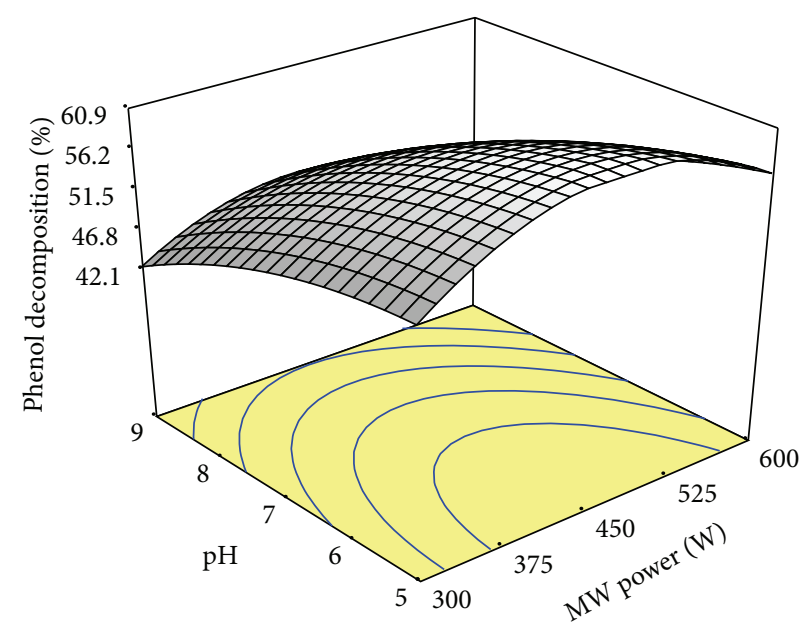

(c)

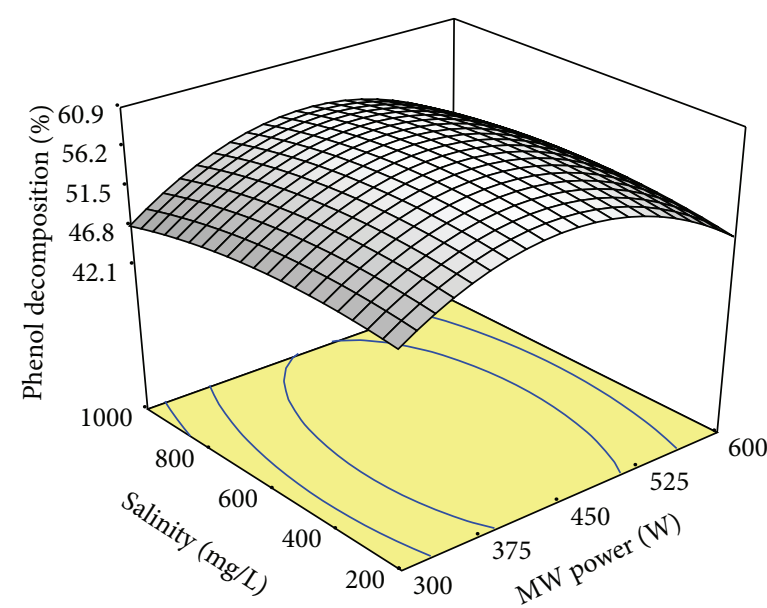

(b)

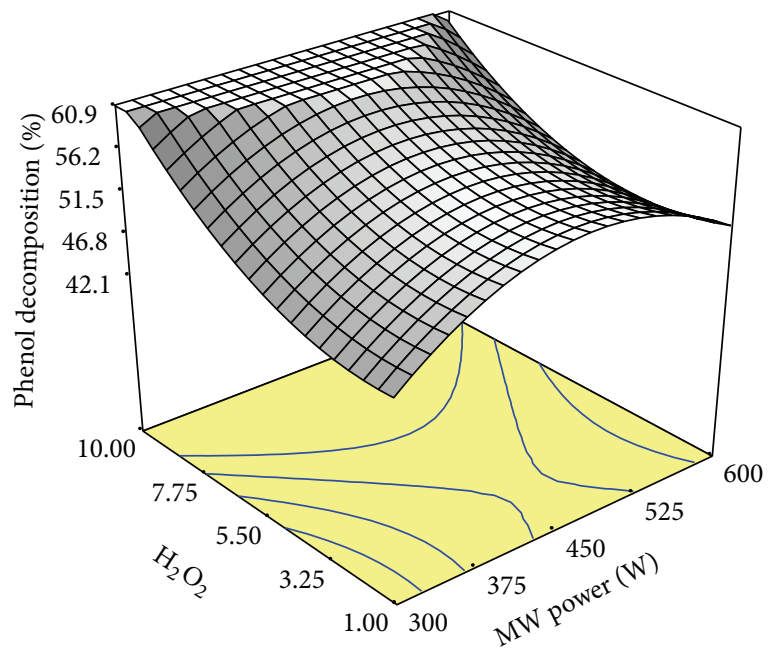

(d)

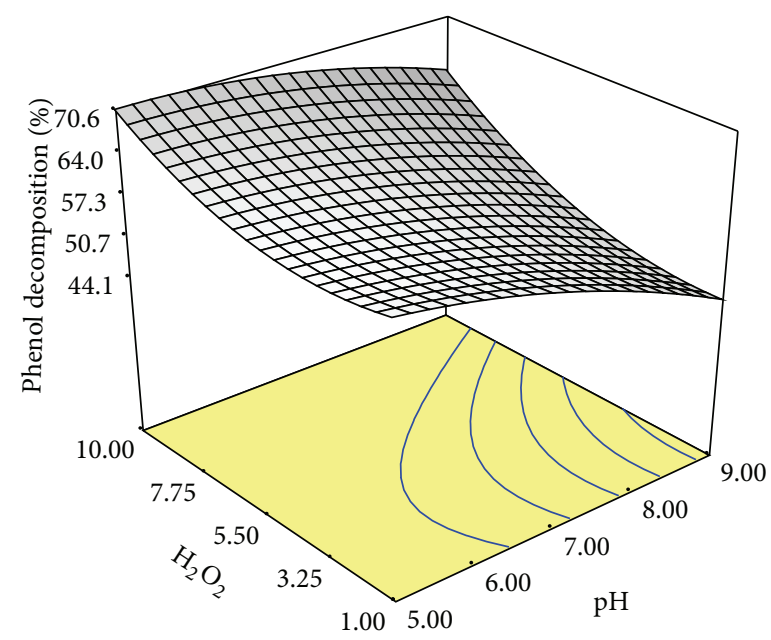

(e)

Figure 6: 3D surface plot with counterdiagram presenting the effect of output MW power, irradiation time, salinity, pH, and initial $\mathrm{H}_{2} \mathrm{O}_{2}$ dosage (v/v) on phenol decomposition efficiency. 
Figure 6(a) represents the effects of varying initial MW output power and irradiation time on removal efficiency of phenol (\%) at constant salinity $600 \mathrm{mg} / \mathrm{L}, \mathrm{pH} 7.0$, and initial $\mathrm{H}_{2} \mathrm{O}_{2}$ concentration $5.5 \%$. It is obvious that both the initial MW power and irradiation time have more powerful effect on response factor. However, the removal efficiency of phenol increases with an increase initial MW power from 300 to $525 \mathrm{~W}$ and further increase in initial MW power would decrease the removal efficiency of phenol. Also, it can be observed that there was a region with neither an increasing nor a decreasing trend in response factor. This phenomenon confirms that there was an existence of optimum removal process variables to achieve maximum percentage of phenol removal. According to this interaction effects, the maximum removal efficiency of phenol was $\approx 57.76 \%$ at initial MW power $\approx 450 \mathrm{~W}$ and $\approx 20 \mathrm{~min}$ irradiation time.

Figure 6(b) represents the effects of varying initial MW output power and salinity at irradiation time $20 \mathrm{~min}, \mathrm{pH} 7$, and initial $\mathrm{H}_{2} \mathrm{O}_{2}$ concentration 5.5\%. It is clearly mentioned that the effectiveness of MW power was higher than salinity for phenol decomposition. Although the decomposition percentage was increased by increasing MW power, however, MW higher than 450 would reduce the removal efficiency of phenol.

Figure 6(c) illustrates the effect of varying initial MW output power and $\mathrm{pH}$ on removal efficiency of phenol (\%) at irradiation time $20 \mathrm{~min}$, initial $\mathrm{H}_{2} \mathrm{O}_{2}$ concentration $5.5 \%$, and salinity $600(\mathrm{mg} / \mathrm{L})$. Both $\mathrm{pH}$ and $\mathrm{MW}$ power contributed in phenol removal. The removal (\%) increased at low $\mathrm{pH}$ values and MW ranges from 400 to 500 .

Figure 6(d) shows the effects of varying initial MW output power and initial $\mathrm{H}_{2} \mathrm{O}_{2}$ concentration on removal efficiency of phenol (\%) at irradiation time $20 \mathrm{~min}$, salinity $600(\mathrm{mg} / \mathrm{L})$, and $\mathrm{pH}$ 7. It is obvious that phenol removal (\%) was increased by increase of initial $\mathrm{H}_{2} \mathrm{O}_{2}$ concentration at optimum 400-500 MW power.

Figure 6(e) represents the effects of varying $\mathrm{pH}$ and initial $\mathrm{H}_{2} \mathrm{O}_{2}$ concentration on removal efficiency of phenol (\%) at irradiation time $20 \mathrm{~min}$, salinity $600(\mathrm{mg} / \mathrm{L})$, and $\mathrm{MW}$ power 450. Both $\mathrm{pH}$ and hydrogen peroxide have interactive effects on phenol removal (\%). The maximum removal (\%) was obtained at highest initial $\mathrm{H}_{2} \mathrm{O}_{2}$ concentration and lowest $\mathrm{pH}$ value.

These observed positive interactions were further confirmed, substantiated by analyzing the $F$ statistics and $P$ values from Table 4; it was found that the $A, B, C, D, E$, $A^{2}, B^{2}, C^{2}, D^{2}, E^{2}$, and $A B, A C, A D, A E, B C, B D, B E, C D$, $C E, D E$ terms were of high and moderate significance in explaining the individual and interaction effects, respectively; that is, the large values of $F$ test for all regressions imply that phenol removal efficiency can be adequately explained by the model equation and the smaller the value of " $P$," the more significant the corresponding coefficient term (i.e., the pattern of interaction among the factors) [40-42]. Table 4 shows that the interaction of initial $\mathrm{pH}$ and $\mathrm{H}_{2} \mathrm{O}_{2}$ was significant with $P$ values $<0.0001$ and was found to be solely responsible for achieving a relatively higher removal percentage as predicted by the 3D response surface (Figure 6) and this is evident from (7), while negligible effect occurred

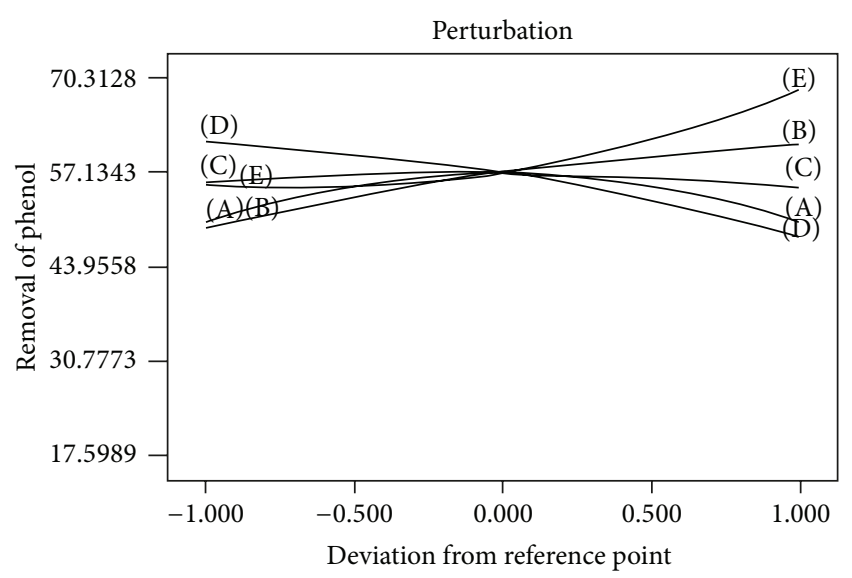

Design Expert plot

Removal of phenol

Actual factors
(A) Power $=450.00$
(D) $\mathrm{pH}=7.00$
(B) Time $=20.00$
(E) $\mathrm{H}_{2} \mathrm{O}_{2}=5.50$
(C) Salinity $=600.00$

FIGURE 7: Perturbation plots showing the optimum values of the tested variables.

by changing initial salinity $(C)$ which was reflected by the corresponding " $P$ " value $(P \approx 0.71)$.

The increase in phenol removal efficiency with increase of hydrogen peroxide concentration may be due to the increase of $\mathrm{HO}^{\circ}$ radicals production from $\mathrm{H}_{2} \mathrm{O}_{2}$ due to the excitation of molecules to higher vibrational and rotational levels under microwave electromagnetic irradiation field that leads, according to the stated hypothesis, to mechanochemical dissociation with the formation of hydroxyl radical groups. The formed hydroxyl radical is highly powerful oxidizing agent having an oxidation potential of $2.33 \mathrm{~V}$, which may undergo a variety of rapid and nonselective reactions with most organic and many inorganic solutes, the most important being hydroxylation and oxidation removal of phenol [7]. This indicates that the existence of superheated aqueous phases at $\mathrm{MW} / \mathrm{H}_{2} \mathrm{O}_{2}$ system may lead to phenol pyrolysis which is important in removal pathways. But according to Zalat and Elsayed [32] it was believed that phenol removal is not due to selective heat effect only; however, thermal and nonthermal effects are responsible for the removal enhancement mechanism by MW irradiation.

The effect of each factor was further assessed by the use of perturbation plots (Figure 7) to show the comparative effects of all independent variables on phenol removal efficiency. In this study, a perturbation curvature confirmed that phenol removal efficiency was very sensitive to the four variable factors: initial MW power, irradiation time, initial $\mathrm{pH}$, and initial hydrogen peroxide concentration. The comparatively semiflatsalinity curve shows less sensitivity of phenol removal efficiency towards the salinity. Thus, the salinity of aqueous solution with the studied range of experiments has no major 
TABLE 5: Optimum values of the process parameter for maximum phenol decomposition efficiency under MW process.

\begin{tabular}{lcccccc}
\hline Treatment Process & Input power (Watt) & Time (min) & Salinity (mg/L) & pH & $\mathrm{H}_{2} \mathrm{O}_{2}$ (\%) & $\begin{array}{c}\text { Phenol decomposition \% } \\
\text { Experimental } \\
\text { Predicted }\end{array}$ \\
\hline MW Process & 439 & 24.22 & 574.10 & 5.10 & 10.00 & 75.70 \\
\hline
\end{tabular}

function in the removal efficiency of phenol compared to the other four factors.

Furthermore, the optimization process was carried out to determine the optimum value of phenol removal efficiency, using the Design Expert 8.0.1.7 software. Accordingly, the optimum working conditions for maximum phenol removal percentage under $\mathrm{MW} / \mathrm{H}_{2} \mathrm{O}_{2}$ treatment process were presented in Table 5 . The predicted maximum removal percentage was $\approx 72.90 \%$ at initial MW power of $439 \mathrm{~W}$, irradiation time of $24.22 \mathrm{~min}$, solution salinity of $574.1 \mathrm{mg} / \mathrm{L}$, initial $\mathrm{pH}$ of 5.0, and initial $\mathrm{H}_{2} \mathrm{O}_{2}$ concentration of $10 \%$. To support the optimized data as given by numerical modeling under optimized conditions, confirmatory experiments were conducted with parameters as evaluated using the quadratic model, and the experimental phenol removal percentage obtained was $75.70 \%$ (Table 5). The experimental results approximately agree with those obtained using response surface analysis, confirming that RSM can be used effectively to optimize process parameters in a complex process using the statistical design of experiments. Also, it confirmed the good fit of the quadratic model to explain the relationship between the studied variable factors and the response (removal efficiency of phenol) by $\mathrm{MW} / \mathrm{H}_{2} \mathrm{O}_{2}$ treatment process. Standard deviation and percent error were calculated for validation of experiments. Recording average of $\approx 1.98$ and $3.70 \%$, respectively, indicating that process optimization by RSM was able and reliable to optimize phenol removal by $\mathrm{MW} / \mathrm{H}_{2} \mathrm{O}_{2}$ treatment process.

\section{Conclusions}

The removal efficiency of phenol under MW treatment processes under different operating conditions increases with increasing MW output power and irradiation times. Also, the phenol removal (\%) at different initial phenol concentrations (10-50 mg/L) was almost unchanged under studied MW treatment process (ranged from $\approx 49.43 \pm 0.95$ to $52.29 \pm$ 0.40 after $40 \mathrm{~min}$ ) indicating that the removal efficiency of phenol by MW irradiation was not factor of phenol initial concentration in the studied range of concentrations.

A kinetic study confirmed that the overall phenol removal rate follows zero-order kinetic model at low MW power (100 and $150 \mathrm{~W}$ ) and first-order kinetics at higher MW power (300-600 W) for initial phenol concentrations (10-25 mg/L). However, kinetic reaction shifted to second-order kinetic model for initial phenol concentration of $50 \mathrm{mg} / \mathrm{L}$ at $450 \mathrm{~W}$ MW power.

A combined process of $\mathrm{H}_{2} \mathrm{O}_{2}$ with $\mathrm{MW}$ improves the removal efficiency of phenol as proved by RSM. Where, $\mathrm{MW} / \mathrm{H}_{2} \mathrm{O}_{2}$ system improves the generation of hydroxyl radicals from $\mathrm{H}_{2} \mathrm{O}_{2}$ due to the excitation of molecules to higher vibrational and rotational levels. Optimization of the process variables for phenol removal using RSM by employing CCD design matrix of experiments was as follows: MW power output of 439 Watt, irradiation time of $24.22 \mathrm{~min}$, salinity of $574.10 \mathrm{mg} / \mathrm{L}, \mathrm{pH} 5.10$, and initial $\mathrm{H}_{2} \mathrm{O}_{2}$ concentration of $10.00 \%(\mathrm{v} / \mathrm{v})$ with predicted and experimental percentage removal of phenol of $72.90 \%$ and $75.70 \%$, respectively.

Finally, it can be proposed that MW radiation with $\mathrm{H}_{2} \mathrm{O}_{2}$ is an effective treatment method for the removal of phenol from petroleum refinery wastewater in a batch system. Future work is recommendable in an attempt to apply this treatment system in a continuous reactor.

\author{
Abbreviation \\ AOP: Advanced oxidation process \\ MW: Microwave \\ RSM: Response surface methodology \\ CCD: The central composite design \\ W: Watt \\ $\mathrm{C}_{o}: \quad$ Initial phenol concentration $(\mathrm{mg} / \mathrm{L})$ \\ $C_{t}: \quad$ Phenol concentration at any time $(\mathrm{mg} / \mathrm{L})$ \\ $R^{2}$ : $\quad$ Correlation coefficient \\ $K_{1}$ : $\quad$ Zero-order rate constant ( $\left.\mathrm{mg} / \mathrm{min}\right)$ \\ $K_{2}: \quad$ First-order rate constant $\left(\mathrm{min}^{-1}\right)$ \\ $K_{3}$ : $\quad$ Second-order rate constant $\left(\mathrm{mg}^{-1} \mathrm{~min}^{-1}\right)$ \\ ERRSQ: The sum of the squares of errors \\ HYBRID: The hybrid fractional error function \\ $x_{i}, x_{j}: \quad$ Independent variables \\ $Y$ : $\quad$ Predicted response.
}

\section{Greek Letters}

$\alpha$ : Variables for the axial points

$\beta_{i}$ : Interaction coefficient

$\beta_{o}$ : The constant model coefficient.

\section{Conflict of Interests}

The authors declare that there is no conflict of interests regarding the publication of this paper.

\section{References}

[1] B. Chen, M. Yuan, and H. Liu, "Removal of polycyclic aromatic hydrocarbons from aqueous solution using plant residue materials as a biosorbent," Journal of Hazardous Materials, vol. 188, no. 1-3, pp. 436-442, 2011.

[2] T. Sasaki and S. Tanaka, "Adsorption behavior of some aromatic compounds on hydrophobic magnetite for magnetic separation," Journal of Hazardous Materials, vol. 196, pp. 327-334, 2011. 
[3] T. P. Ryynänen, Reduction of waste water loads at petrochemical plants [M.S. thesis], Department of Chemical and Biological Engineering, Division of Chemical Environmental Science, Chalmers University of Technology, Göteborg, Sweden, 2011.

[4] S. Ishak, A. Malakahmad, and M. H. Isa, "Refinery wastewater biological treatment: a short review," Journal of Scientific and Industrial Research, vol. 71, no. 4, pp. 251-256, 2012.

[5] K. F. Al-Sultani and F. A. Al-Seroury, "Characterization the removal of phenol from aqueous solution in fluidized bed column by rice husk adsorbent," Research Journal of Recent Sciences, vol. 1, no. ISC-2011, pp. 145-151, 2012.

[6] B. Mukhetjee, J. Turner, and B. Wrenn, "Effect of oil composition on chemical dispersion of crude oil," Environmental Engineering Science, vol. 28, no. 7, pp. 497-506, 2011.

[7] B. R. Prasannakumar, I. Regupathi, and T. Murugesan, "An optimization study on microwave irradiated, decomposition of phenol in the presence of $\mathrm{H}_{2} \mathrm{O}_{2}$," Journal of Chemical Technology and Biotechnology, vol. 84, no. 1, pp. 83-91, 2009.

[8] S. Beszédes, Z. László, Z. H. Horvàth, G. Szabó, and C. Hodúr, "Comparison of the effects of MW irradiation with different intensities on the biodegradability of sludge from the dairyand meat-industry," Bioresource Technology, vol. 102, pp. 814821, 2011.

[9] W. Li, Q. Zhou, and T. Hua, "Removal of organic matter from landfill leachate by advanced oxidation processes: a review," International Journal of Chemical Engineering, vol. 2010, Article ID 270532, 10 pages, 2010.

[10] J. P. Robinson, S. W. Kingman, and O. Onobrakpeya, "Microwave-assisted stripping of oil contaminated drill cuttings," Journal of Environmental Management, vol. 88, no. 2, pp. 211218, 2008.

[11] L. P. Yang, W. Y. Hu, H. M. Huang, and B. Yan, "Degradation of high concentration phenol by ozonation in combination with ultrasonic irradiation," Desalination and Water Treatment, vol. 21, no. 1-3, pp. 87-95, 2010.

[12] I. D. Manariotis, H. K. Karapanagioti, and C. V. Chrysikopoulos, "Degradation of PAHs by high frequency ultrasound," Water Research, vol. 45, no. 8, pp. 2587-2594, 2011.

[13] Y.-C. Chien, "Field study of in situ remediation of petroleum hydrocarbon contaminated soil on site using microwave energy," Journal of Hazardous Materials, vol. 199-200, pp. 457461, 2012.

[14] P. Klan and V. Cirkva, "Microwave photochemistry," in Microwaves in Organic Synthesis, A. Loupy, Ed., Chapter 14, pp. 463486, Wiley-VCH, 2002.

[15] Y. F. Zhao and J. Chen, "Applications of microwaves in nuclear chemistry and engineering," Progress in Nuclear Energy, vol. 50, no. 1, pp. 1-6, 2008.

[16] Y. Y. Shu, T. L. Lai, H.-S. Lin, T. C. Yang, and C.-P. Chang, "Study of factors affecting on the extraction efficiency of polycyclic aromatic hydrocarbons from soils using open-vessel focused microwave-assisted extraction," Chemosphere, vol. 52, no. 10, pp. 1667-1676, 2003.

[17] Y. Y. Shu, R. C. Lao, C. H. Chiu, and R. Turle, "Analysis of polycyclic aromatic hydrocarbons in sediment reference materials by microwave-assisted extraction," Chemosphere, vol. 41, no. 11, pp. 1709-1716, 2000.

[18] D.-H. Han, S.-Y. Cha, and H.-Y. Yang, "Improvement of oxidative decomposition of aqueous phenol by microwave irradiation in $\mathrm{UV} / \mathrm{H}_{2} \mathrm{O}_{2}$ process and kinetic study," Water Research, vol. 38, no. 11, pp. 2782-2790, 2004.
[19] J. G. Mei, S. M. Yu, and J. Cheng, "Heterogeneous catalytic wet peroxide oxidation of phenol over delaminated Fe-Ti-PILC employing microwave irradiation," Catalysis Communications, vol. 5, no. 8, pp. 437-440, 2004.

[20] A. Zhihui, Y. Peng, and L. Xiaohua, "Degradation of 4Chlorophenol by microwave irradiation enhanced advanced oxidation processes," Chemosphere, vol. 60 , no. 6, pp. 824-827, 2005.

[21] M. A. Aramendía, J. C. Colmenares, S. López-Fernández et al., "Photocatalytic degradation of chlorinated pyridines in titania aqueous suspensions," Catalysis Today, vol. 138, no. 1-2, pp. 110$116,2008$.

[22] D. H. Lataye, I. M. Mishra, and I. D. Mall, "Adsorption of 2picoline onto bagasse fly ash from aqueous solution," Chemical Engineering Journal, vol. 138, no. 1-3, pp. 35-46, 2008.

[23] L. L. Bo, M. W. Li, X. Quan, S. Chen, D. M. Xue, and C. B. Li, "Treatment of high concentration organic wastewater by microwave catalysis," in Proceedings of the 3rd International Conference on Microwave and Millimeter Wave Technology Proceedings, Beijing, China, 2002.

[24] D. H. Bremner, R. Molina, F. Martínez, J. A. Melero, and Y. Segura, "Degradation of phenolic aqueous solutions by high frequency sono-Fenton systems (US- $\mathrm{Fe}_{2} \mathrm{O}_{3} / \mathrm{SBA}-15-\mathrm{H}_{2} \mathrm{O}_{2}$ )," Applied Catalysis B, vol. 90, no. 3-4, pp. 380-388, 2009.

[25] M. R. Doosti, R. Kargar, and M. H. Sayadi, "Water treatment using ultrasonic assistance: a review," Proceedings of the International Academy of Ecology and Environmental Sciences, vol. 2, no. 2, pp. 96-110, 2012.

[26] Y. Qingshan, L. Yongjin, and M. Lingling, "Kinetics of photocatalytic degradation of gaseous organic compounds on modified $\mathrm{TiO}_{2} / \mathrm{AC}$ composite photocatalyst," Chinese Journal of Chemical Engineering, vol. 20, no. 3, pp. 572-576, 2012.

[27] C. Capellos and B. H. Bielski, Kinetic Systems: Mathematical Description of Chemical Kinetics in Solution, Wiley-Interscience, New York, NY, USA, 1972.

[28] Y. C. Wong, Y. S. Szeto, W. H. Cheung, and G. McKay, "Adsorption of acid dyes on chitosan-equilibrium isotherm analyses," Process Biochemistry, vol. 39, no. 6, pp. 693-702, 2004.

[29] J. Y. Farah, N. S. El-Gendy, and L. A. Farahat, "Biosorption of Astrazone Blue basic dye from an aqueous solution using dried biomass of Baker's yeast," Journal of Hazardous Materials, vol. 148, no. 1-2, pp. 402-408, 2007.

[30] G. Cimino, A. Passerini, and G. Toscano, "Removal of toxic cations and $\mathrm{Cr}(\mathrm{VI})$ from aqueous solution by hazelnut shell," Water Research, vol. 34, no. 11, pp. 2955-2962, 2000.

[31] M. Papadaki, R. J. Emery, M. A. Abu-Hassan, A. Díaz-Bustos, I. S. Metcalfe, and D. Mantzavinos, "Sonocatalytic oxidation processes for the removal of contaminants containing aromatic rings from aqueous effluents," Separation and Purification Technology, vol. 34, no. 1-3, pp. 35-42, 2004.

[32] O. A. Zalat and M. A. Elsayed, "A study on microwave removal of pyridine from wastewater," Journal of Environmental Chemical Engineering, vol. 1, no. 3, pp. 137-143, 2013.

[33] V. L. Vaks, G. A. Domrachev, Y. L. Rodygin, D. A. Selivanovskii, and E. I. Spivak, "Dissociation of water by microwave radiation," Radiophysics and Quantum Electronics, vol. 37, no. 1, pp. 85-88, 1994.

[34] P. M. Robitaille, "Water, hydrogen bonding, and the microwave background," Progress in Physics, vol. 2, pp. L5-L8, 2009.

[35] X. Quan, Y. Zhang, S. Chen, Y. Zhao, and F. Yang, "Generation of hydroxyl radical in aqueous solution by microwave energy 
using activated carbon as catalyst and its potential in removal of persistent organic substances," Journal of Molecular Catalysis A: Chemical, vol. 263, no. 1-2, pp. 216-222, 2007.

[36] D. Zhao, J. Cheng, and M. R. Hoffmann, "Kinetics of microwave-enhanced oxidation of phenol by hydrogen peroxide," Frontiers of Environmental Science and Engineering in China, vol. 5, no. 1, pp. 57-64, 2011.

[37] D. Zhao and K. Fei, "Synergetic kinetics of phenol degradation in water by using microwave $/ \mathrm{H}_{2} \mathrm{O}_{2}$ system," Journal of Chemical Industry and Engineering, vol. 59, no. 1, pp. 101-105, 2008.

[38] A. I. Khuri and J. A. Cornell, Response Surfaces: Design and Analysis, Marcel Dekker, New York, NY, USA, 1987.

[39] J. Virkutyte, V. Vičkačkaite, and A. Padarauskas, "Sonooxidation of soils: degradation of naphthalene by sono-Fentonlike process," Journal of Soils and Sediments, vol. 10, no. 3, pp. 526-536, 2010.

[40] M. Clarke and R. E. Kempson, Introduction To the Design and Analysis of Experiments, Arnold, London, UK, 1997.

[41] K. Ravikumar, K. Pakshirajan, T. Swaminathan, and K. Balu, "Optimization of batch process parameters using response surface methodology for dye removal by a novel adsorbent," Chemical Engineering Journal, vol. 105, no. 3, pp. 131-138, 2005.

[42] R. Wächter and A. Cordery, "Response surface methodology modelling of diamond-like carbon film deposition," Carbon, vol. 37, no. 10, pp. 1529-1537, 1999. 

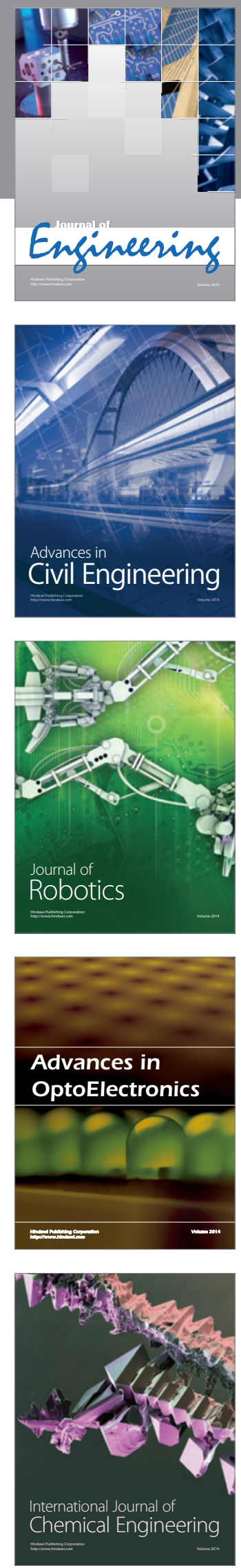

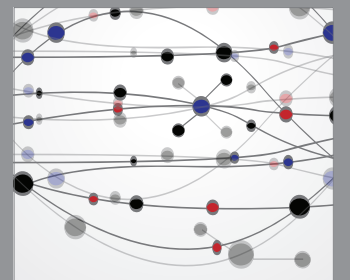

The Scientific World Journal
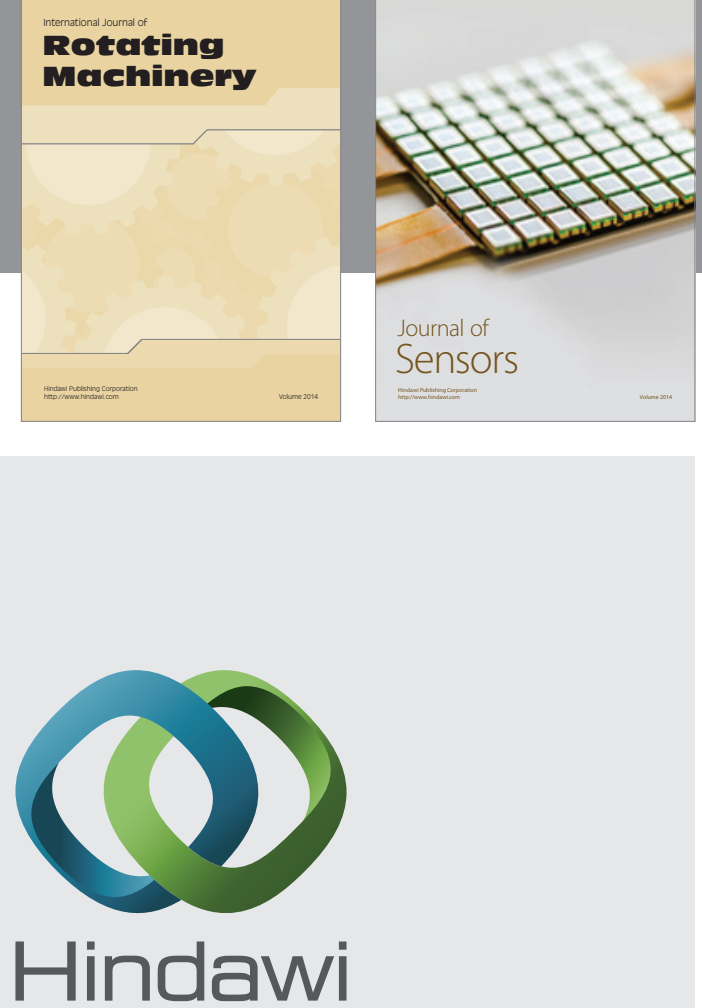

Submit your manuscripts at http://www.hindawi.com
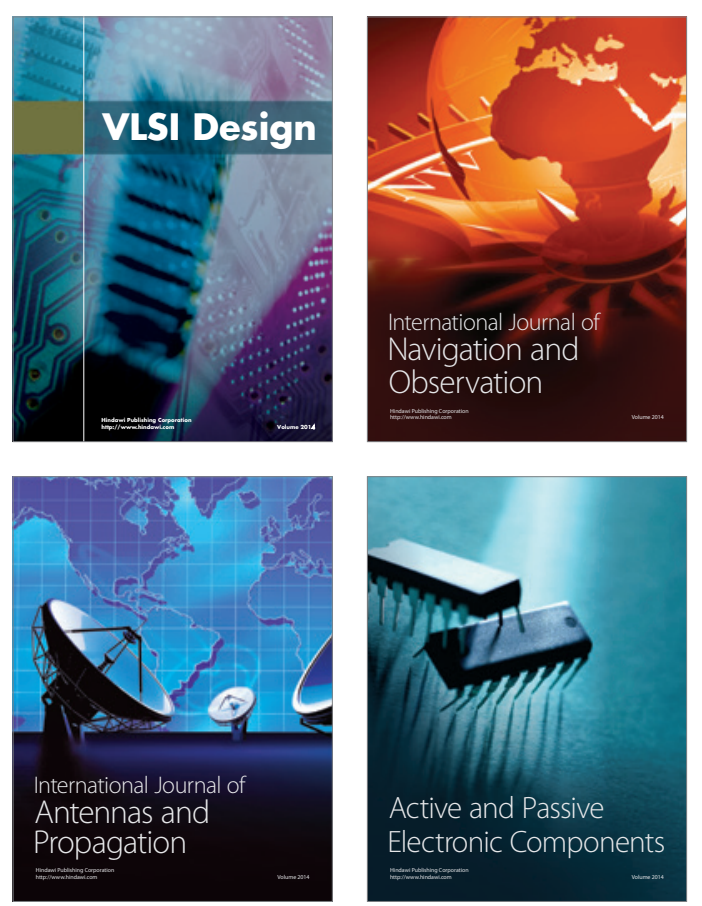
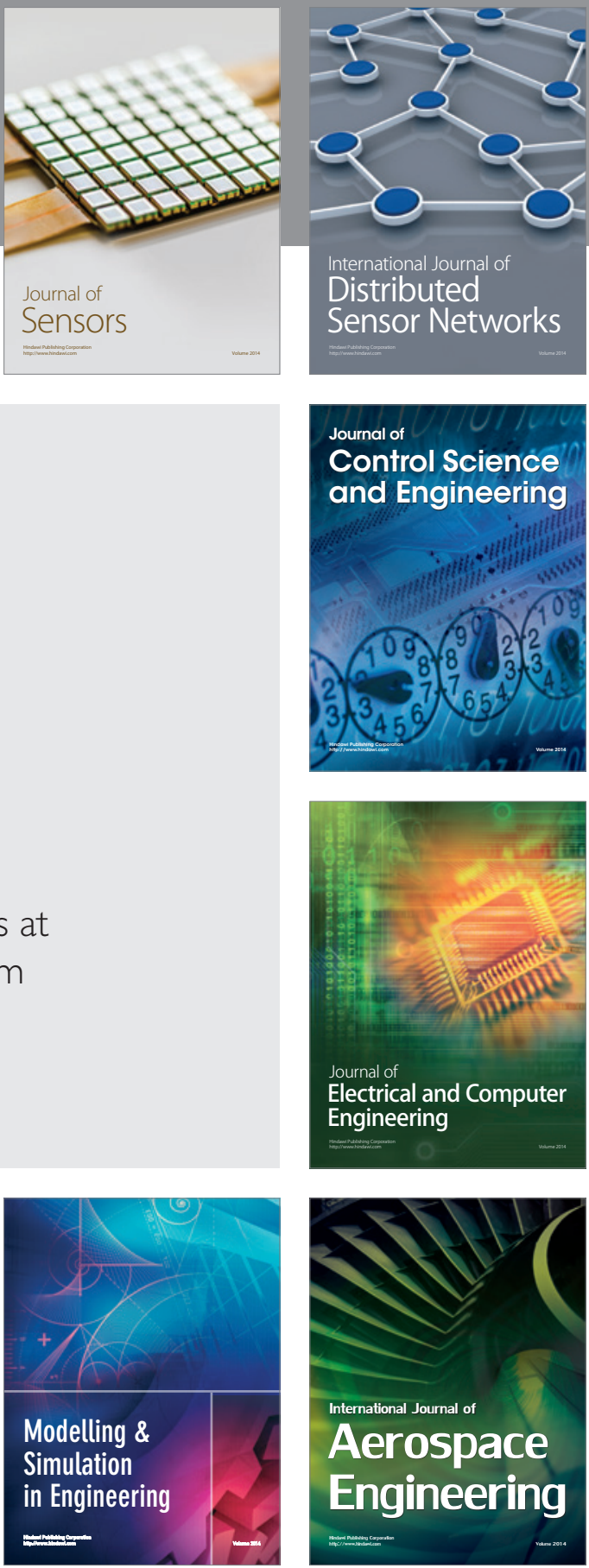

Journal of

Control Science

and Engineering
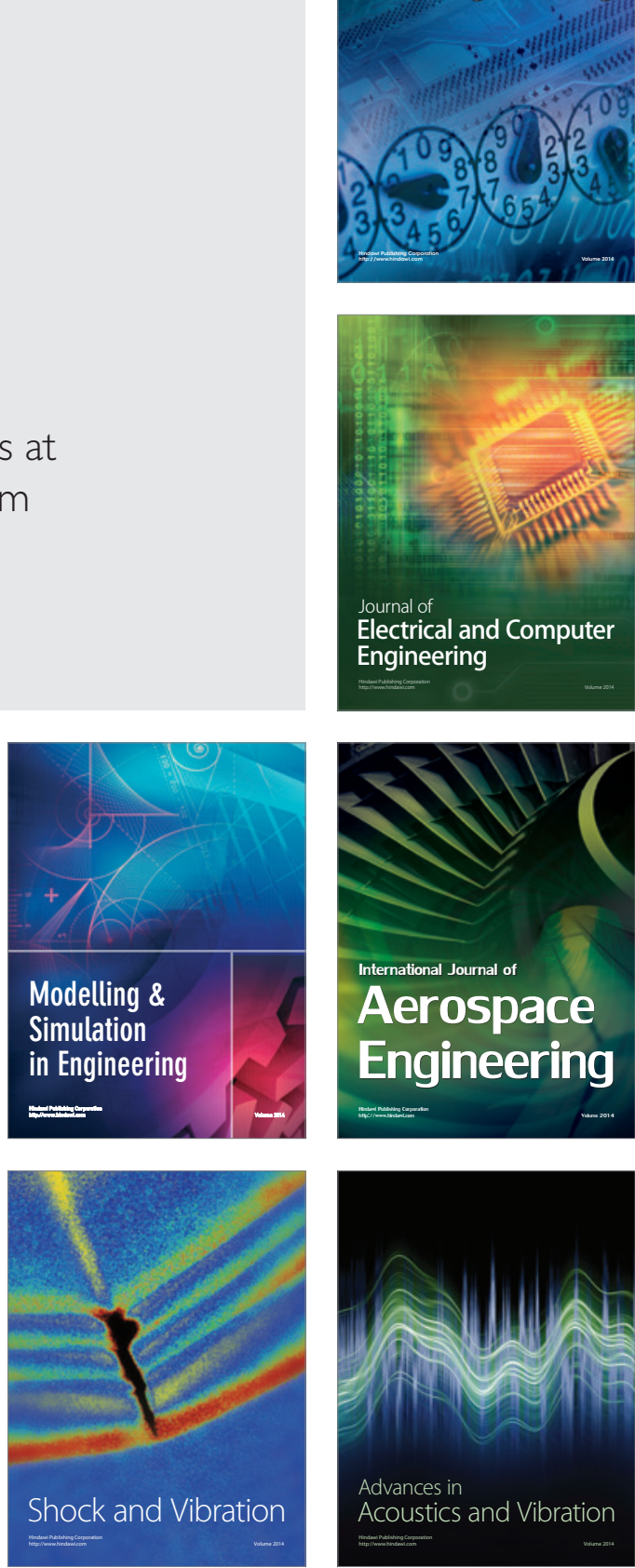